\title{
COMPARISON OF EMOTIONAL INTELLIGENCE IN WORKING COUPLES IN GORGAN
}

\author{
Khadije Khatiri $^{1}$, Kobra Kazemian Moghadam ${ }^{2, *}$, Fatemeh Rabiee ${ }^{3}$ \\ ${ }^{1}$ Department of Educational Sciences, Sari Branch, Islamic Azad University, Sari, Iran \\ ${ }^{2}$ Department of Psychology, Islamic Azad University, Dezful Branch, Dezful, Iran \\ ${ }^{3}$ Master of art in counseling and Guidance, Islamic Azad University, Iran, Rudehen
}

k.kazemian@yahoo.com

\begin{abstract}
The present study was formulated to determine emotional health in working couples of Gorgan city in 2010.Samples were selected via cluster sampling method after deriving the statistical facts about working males and females in Gorgan City and finally, 100 people (50 couples) were selected. BarOn questionnaire was selected to measure emotional intelligence due to comprehensiveness, simplicity, and conformity to Iranian culture. The collected data were subjected to descriptive statistics (mean and standard deviation) in SPSS Software. Then, the data were analyzed through inferential statistics. The results obtained from the present study showed that there is no significant difference in emotional intelligence of working females (1.995) compared to their working husbands $(1.960)$.
\end{abstract}

Keywords: emotional intelligence, working couples, Bar-On.

\section{1- INTRODUCTION}

Thought and emotion cannot be considered to be separate in structure of emotional intelligence (Syavorchi \& Jan, 2001). Today, on the basis of clinical experiences, it is claimed that thought without emotion makes satisfactory decision-making impossible. The key factor for favorable decision-making is awareness of one's own and surrounding people's feelings leading to more confident decision-making. Investigations on emotional intelligence have been recently started. Emotional it should be noted that intelligence cannot be considered as the only factor for having a comfortable life (Bar-on, 1997).

The emotional intelligence is a topic that attempts to explain and interprets the man excitement, feeling and capability status (Hassan zadeh, 2007). The emotional intelligence has been defined as an ability to understand and comprehend the emotions in order for assessing thoughts, manners and to put them in a way that makes emotion and intelligent growth and elevation (Goleman, 1995).

On the other hand, authors have shown that happy and fortunate couples are those who are accurately engaged in understanding, recognizing, adjusting, and expressing your and others' emotions; the higher the abilities they have, the more fortunate they will be. The findings are consistent with the literature about emotional intelligence (Bradberry \& Griverz, 2005). In this hypothesis, it is claimed that people have different abilities to organize their emotions. That's why it is presumably thought that studies around marital life acknowledge that those with higher emotional intelligence may make use of them in their marital life as well as their occupational activities. In addition, various abilities to understand emotions may have significant relationship with optimal estimations in marital life. Emotional intelligence 
structure is a new and influential structure; the more accurate this structure is defined, the more influential it will be.

We also believe that emotional intelligence in work place is a unique perspective in order to increase occupational progress. Considering the importance of emotional intelligence in marital life, the present study was formulated to determine this factor in working couples of Gorgan city in 2010. We hypothesized that emotional intelligence in working females is higher than that in their working husbands.

Theoretical definition: Ability to understand surroundings properly, self-motivation, selfawareness in order to facilitate thinking and relationship (Mayer \&Salovey, 1990).

Operational definition: Emotional intelligence in the present study is the score one gets in Bar-On test. According to this test, the subjects are tested in terms of 117 questions and 15 scales.

\section{2- METHODOLOGY}

Population

Study population was composed of all working males and females in governmental organizations and offices in Gorgan City in 2010. Samples were selected via cluster sampling method after deriving the statistical facts about working males and females in Gorgan City and finally, 100 people (50 couples) were selected.

Emotional intelligence questionnaire

Bar-On questionnaire was selected to measure emotional intelligence due to comprehensiveness, simplicity, and conformity to Iranian culture. It reports non-cognitive intelligence (emotional, personal, and social) and is applicable in educational, industrial, clinical, and medicinal atmospheres. The test is composed of 117 questions and 15 scales. The answers were based on Likert scale with five options (i.e. absolutely agree, agree, moderately agree, disagree, absolutely disagree). The scales are emotional self-awareness, assertiveness, self-regard, self-actualization, independence, empathy, social responsibility, interpersonal relationship, reality testing, flexibility, problem solving, stress tolerance, impulse control, optimism, and happiness (Bar-on, 1997). Validity (0.9) and reliability of the tool were confirmed by help of experts.

Statistical analysis

The collected data were subjected to descriptive statistics (mean and standard deviation) in SPSS Software. Then, the data were analyzed through inferential statistics.

\section{3- RESULT}

Table 1. Frequency distribution of gender in the population

\begin{tabular}{|l|l|l|l|l|}
\hline Gender & Frequency & Percent & $\begin{array}{l}\text { Frequency } \\
\text { percent }\end{array}$ & $\begin{array}{l}\text { Cumulative } \\
\text { percent }\end{array}$ \\
\hline Male & 50 & 50.0 & 50.0 & 50.0 \\
\hline Female & 50 & 50.0 & 50.0 & 100.0 \\
\hline Total & 100 & 100.5 & 100.0 & \\
\hline
\end{tabular}


Table (1) shows the subjects in terms of gender. As it can be seen, from 100 persons, 50 were males and 50 were females.

Table 2. Frequency distribution of age in the population

\begin{tabular}{|l|l|l|l|l|}
\hline Age & Frequency & Percentage & $\begin{array}{l}\text { Frequency } \\
\text { percentage }\end{array}$ & $\begin{array}{l}\text { Cumulative } \\
\text { percentage }\end{array}$ \\
\hline $18-25$ & 9.0 & 9.0 & 9.0 & 9.0 \\
\hline $26-30$ & 12.0 & 12.0 & 12.0 & 21.0 \\
\hline $31-35$ & 32.0 & 32.0 & 32.0 & 53.0 \\
\hline $36-40$ & 42.0 & 42.5 & 42.5 & 95.0 \\
\hline $41-45$ & 5.0 & 5.0 & 5.0 & 100.0 \\
\hline Total & 100.0 & 100.0 & 100.0 & \\
\hline
\end{tabular}

Table (2) shows the subjects in terms of age of population. As it can be seen from this table, from 100 persons, 9 were 18-25 years old, 12 were 26-30 years old, 32 were 31-35 years old, 42 were $36-40$ years old, and 5 were $41-45$ years old.

Table3. Frequency distribution of education degree in the population

\begin{tabular}{|l|l|l|l|l|}
\hline Education degree & Frequency & Percentage & $\begin{array}{l}\text { Frequency } \\
\text { percentage }\end{array}$ & $\begin{array}{l}\text { Cumulative } \\
\text { percentage }\end{array}$ \\
\hline High school diploma & 12 & 12.0 & 12.0 & 12.0 \\
\hline Associate degree & 16 & 16.0 & 16.0 & 28.0 \\
\hline Bachelor & 66 & 66.0 & 66.0 & 94.0 \\
\hline Master & 6 & 6.0 & 6.0 & 100.0 \\
\hline Total & 100 & 100.0 & 100.0 & \\
\hline
\end{tabular}

Table (3) shows the subjects in terms of their education degree. It can be seen that from 100 persons, 12 had high school diploma, 16 had associate degree, 66 had bachelor degree, and 6 had master degree.

Table 4. Frequency distribution of professional experience in the population

\begin{tabular}{|l|l|l|l|l|}
\hline $\begin{array}{l}\text { Professional } \\
\text { experience }\end{array}$ & Frequency & Percentage & $\begin{array}{l}\text { Frequency } \\
\text { percentage }\end{array}$ & $\begin{array}{l}\text { Cumulative } \\
\text { percentage }\end{array}$ \\
\hline$<10$ years & 21 & 21.0 & 21.0 & 21.0 \\
\hline $10-20$ years & 56 & 56.0 & 56.0 & 77.0 \\
\hline $21-30$ years & 23 & 23.0 & 23.0 & 100.0 \\
\hline Total & 100 & 100.0 & 100.0 & \\
\hline
\end{tabular}

Furthermore, table (4) shows the subjects in terms of their professional experience. As it can be seen from the total 100 subjects, 21 had $<10$ years professional experience, 56 had between 10 and 20 years professional experience, and 23 had between 21 and 30 years professional experience. 
In order to determine the hypothesis (i.e. emotional intelligence in working females is higher than that in their working husbands), t-test was adopted.

Table 5. t-test results for the study's hypothesis

\begin{tabular}{|l|l|l|l|l|l|l|}
\hline Gender & Number & Mean & Std. deviation & $\mathrm{t}$ & Freedom degree & Probability \\
\cline { 1 - 4 } & 50 & 1.960 & 0.30923 & 0.424 & 98 & 0.672 \\
\hline Female & 50 & 1.995 & 0.50658 & & & \\
\hline
\end{tabular}

As it can be seen in the above table, there is no significant difference in emotional intelligence of working females (1.995) compared to their working husbands (1.960). Also, as $\mathrm{t}$ value is smaller than the table value (1.984) and probability being higher than $0.05, \mathrm{H} 1$ is denied and $\mathrm{H} 0$ is affirmed.

\section{4- DISCUSSION}

The results obtained from the present study showed that there is no significant difference in emotional intelligence of working females (1.995) compared to their working husbands (1.960). This is consistent with the results obtained by Alijani, Razavi, Asadi, and Khosravi (quoted Esmaeeli, 2004). Our results are also consistent with those of Veet, Gardner and Stock, Marshal et al, Modrock, Kingerburi and Daus (quoted Esmaeeli, 2004). Moreover, Spatial limitations to choose geographical zone, temporal limitations to present questionnaires and collection of ideas, limitations in choosing education degrees and majors, length of questionnaires and lack of enthusiasm to complete them, lack of accurate control over variables in investigation situations, and difficulty to describe emotional intelligence to some respondents are a few example of the limitations in the present study. After considering the results obtained in the present study, it is recommended to study other factors such as workplace, living place, personal relations and etc. Also, it is recommended that emotional intelligence skills are considered important and effective in workplace and employees are encouraged to increase this ability.

\section{References}

[1] Hassan zadeh, R, (2007). The motivation and excitement. Tehran : Arasbaran Publication

[2] Goleman, D. (1995); Emotional Intelligences: The Theory in Practice; Newyourk: Basic Book.

[3] Bar-on, R. (1997). A Measure of Emotional and Social Intelligence in Chicago. Canadian Journal of Behavioral Science, 18: 123- 137.

[4] Mayer , J. D. \&Salovey, P.(1990). Emotional Intelligence. Imagination, Cognition, and Personality,9.185-211. Personality and Individual Differences. 
[5] Bradberry T., Griverz, J (2005). Emotional intelligence; skills and techniques.Translated by Ganji M., Tehran: Savalan.

[6] Esmaeeli, M. (2004) determination of effect of educating emotional intelligence attributes on mental health increase. $\mathrm{PhD}$ thesis in counseling and guidance, AllamehTabatabayee University.

[7] Syavorchi, J., \& Jan, M. (2001). Emotional intelligence in daily life. Translation, Noori Emam zadehi ., Nasiri ., H Esfahan: Nashr Neveshteh. 